ARTICLE

Received 23 Sep 2015 | Accepted 7 Dec 2015 | Published 19 Jan 2016

\title{
"Confusion is a fundamental state of mind" -On the peculiar intellectual career of global governance in international relations
}

\author{
Matthias Hofferberth ${ }^{1}$
}

\begin{abstract}
More than 20 years after global governance was introduced to the discipline of International Relations (IR), confusion about its conceptual status remains. In fact, how to even speak and think global governance-whether as a description of world politics, as a theoretical perspective to explain it, or as a normative notion to be realized through global policy-remains debated. This state of confusion affects debates within the Political Science subfield of IR as well as dialogue between different disciplines beyond IR. More specifically, the article argues that the current state of confusion exists not because of a lack of debate but rather because of different understandings of global governance that were attached to the concept during its emergence and which are still advanced and reproduced within debates today. These different understandings have their origin in certain real-world and disciplinary dynamics and constitute global governance in present discourse as a "condensation symbol" of different meanings. It is argued that precisely because of this status, global governance has obtained its "celebrity status", within and beyond IR. By structuring different understandings of global governance and by reconstructing real-world and disciplinary contexts of emergence, the article goes beyond stating the obvious and provides a discussion of various sources and consequences of the confusion surrounding global governance. On the basis of this state-of-the-art overview, it is argued that to realize the full potential of global governance in IR and ensure interdisciplinary dialogue beyond it, one needs to engage with the concept and its immanent confusion in a reflective and cautious way by becoming aware of different meanings attached to it instead of arbitrarily reducing the concept to a single meaning to define its conceptual status. This article is published as part of a thematic collection on global governance.
\end{abstract}

\footnotetext{
${ }^{1}$ Department of Political Science and Geography, University of Texas at San Antonio, San Antonio, USA.
} 
"Sorting out how people think about global governance is a challenge". Timothy Sinclair, Global Governance.

\section{$\mathrm{M}$}

Introduction ore than 20 years after Rosenau and Czempiel (1992) introduced the idea of global governance to the subfield of International Relations (IR) and its study of world politics, confusion about its conceptual status remains. As recently argued by Weiss and Wilkinson (2014a: 207), global governance "remains notoriously slippery" as it is now ubiquitously "used and abused by academics and policymakers" alike. At the same time, the concept continues to exercise great attractiveness in and beyond IR and maintains, at least in some circles, a "near-celebrity status" (Barnett and Duvall, 2005: 1). Despite (or maybe precisely because as we will explore below) its conceptual ambiguity, Weiss and Wilkinson (2014b) and others see potential in global governance to overcome major shortcomings of the discipline and initiate broader interdisciplinary dialogue. Put differently, while everyone seems to be somewhat disappointed with global governance and the lack of clarity that prohibits exchange across the disciplines, many still advance and refer to it as an important narrative, within and beyond IR (Barnett and Sikkink, 2008). Such contradicting assessments of the current state of global governance and its potential for studying, explaining and changing world politics leaves the reader, both in and beyond IR, wondering whether to fully embrace or completely abandon the idea. It also calls for a reflective account of the peculiar intellectual career of the concept.

The fundamental confusion surrounding global governance is not new. Ever since its early "mission statements", different authors, some sympathetic to global governance and some not, criticized its vagueness, ambiguity and loose definition (Finkelstein, 1995; Latham, 1999; Sinclair, 2012). Aside from stating what has almost become a cliché, however, there is surprisingly little exploration as to what the root causes of the lasting confusion surrounding global governance might be. I argue that there are two mutually reinforcing layers of confusion. On the one hand, in current debates, global governance has become a disciplinary "condensation symbol" (Kaufer and Carley, 1993). Introduced by some as an analytical concept for studying world politics, its original purpose according to others was to provide insight into and explanation for change (Rosenau, 1992). Thus, as has been pointed out by Dingwerth and Pattberg (2006) and Hofferberth (2015), global governance from its very beginning never was a monolithic bloc. Today, references to global governance continuously imply different meanings simply because different scholars attach different commitments to it. On the other hand and beyond its current invocations, contexts of emergence of global governance need to be considered (Hewson and Sinclair, 1999: 3-5). It is argued that the plethora of different meanings in the current discourse historically originated in particular developments and disciplinary dynamics. While overlapping, for the purpose of analytical precision, the article distinguishes between real-world and disciplinary contexts and dynamics. Both are reconstructed in the ways they influenced academic reflections on and applications of global governance within and beyond IR.

Starting with the current uses of global governance, the article is structured as follows. Drawing on Dingwerth and Pattberg (2006) and Hofferberth (2015), the next section reconstructs different understandings of global governance currently present in the discourse. As such, global governance is advanced interchangeably as a policy notion, an empirical condition and an analytical tool. In addition, implications of these different understandings for IR are considered. Framing global governance either as an unnecessary distraction, a valuable addition or an encompassing new perspective clearly defines different relationships and implies different disciplinary consequences. In a second step, it will be argued that global governance was introduced to challenge previous ways of studying and doing world politics. Consequentially, the origins of the current state of confusion surrounding global governance are discussed historically by considering both real-world as well as disciplinary contexts and dynamics. Unfortunately, by the very yardsticks under which IR was operating at the time (and potentially still is today), innovation and novelty rather than precision and clarity were considered as major assets of new contenders. Hence, while being critical of IR, one can argue that global governance mimicked disciplinary practices recently discussed as problematic (Lake, 2011; Jackson and Nexon, 2013). These and other arguments are summarized in the conclusion to provide a balanced judgment of what global governance offers in analytical and conceptual terms and which practices need to be avoided to realize its full potential.

\section{Current understandings in and of global governance}

As an intellectual abbreviation, global governance carries a world of meaning and different normative assessments whenever it is being invoked. However, unlike other research traditions, which are defined by certain core assumptions known to the initiated and "sophisticates who have learned the research tradition” (Lake, 2011: 468), global governance's world of meaning is specifically diffuse since its conceptual status remains debated. Put differently, Finkelstein's (1995) challenging and foundational "What is Global Governance?" question continues to haunt global governance as different scholars advance different answers. Consequentially, as a condensation symbol, it lacks what Kaufer and Carley (1993: 204-205) discuss as "situational consensus" while featuring a high "situational density" as it is regularly advanced as a term. Taken together, global governance ultimately remains undefined and pregnant with different meanings "whose contents remain a foggy aspiration” (Kaufer and Carley, 1993: 206). Consequentially, references to global governance without specifying which meanings are meant to be invoked only add to and reproduce the general confusion. ${ }^{2}$

While there are contributions discussing global governance and its different meanings in a self-reflective fashion (Hewson and Sinclair, 1999; Ba and Hoffmann, 2005; Dingwerth and Pattberg, 2006; Hofferberth, 2015; Pegram and Acuto, 2015), most authors, for practical reasons, sidestep such debates and refer to global governance to make an argument and advance research agendas by assuming that readers at least share a somewhat similar understanding of the concept. ${ }^{3}$ Given the wide range of different meanings in use, however, such assumptions become problematic as global governance is, among other things, referred to as a policy notion with its origins in the practitioners' discourse (Weiss, 2000), as an analytical tool to study and assess scale and dimensions of global change (Dingwerth and Pattberg, 2006), as well as an empirical condition reflecting how world politics has changed (Karns and Mingst, 2010). In other words, from its very inception, global governance semantically entailed and continues to entail today a wide range of different meanings, including the activities of actors engaged in world politics, the conceptual tools and the ontology to intellectually grasp these, and the paradigmatic description thereof as a new type of world politics (Smouts, 1998: 81-82). Figure 1 depicts these different understandings which, given that global governance is advanced in all three directions and often so without reflection, constitute a state of confusion. 4 


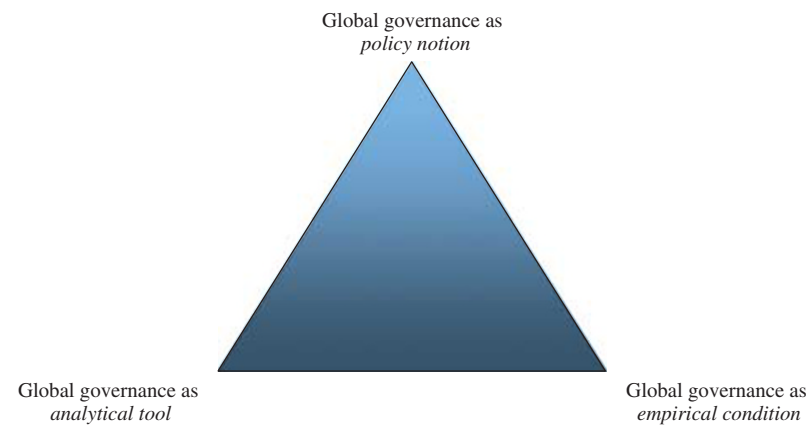

Figure 1 | Ideal Type Understandings of Global Governance.

Adding to the confusion, global governance's relationship to the Political Science subfield of IR remains unclear as well. Obviously, governance and governance theory is a broader and interdisciplinary research field beyond IR which, arguably, has advanced better developed conceptualizations (Mayntz, 2003; Torfing et al., 2012). Adding the adjective "global", however, not only refers to a larger range of (non-state) actors involved in the provision of public goods and the potentially global nature and scope of issues. It also qualitatively changes the concept of governance and relates the debate immediately to the subfield of IR and its own "post-paradigmatic era" (Jackson and Nexon, 2013). Given that the field seems to be constantly in search of grand debates and a collective identity, global governance was discussed and suggested to serve in this narrative capacity (Barnett and Sikkink, 2008) and, in fact, is expected to "come to the rescue" of a subfield "teetering on the abyss of irrelevance (Weiss and Wilkinson, 2014b). What these assessments suggest is the potential of global governance to constitute a new field of study beyond IR which would be no longer limited by state centrism nor only consider the exercise of formal-legal authority. More moderate approaches understand global governance as an addition to current IR theory and "feel comfortable examining global governance with traditional, though expanded, theoretical perspectives" (Hoffmann and Ba, 2005b: 257). Finally, sceptical voices argue that global governance is nothing but a distraction since as "a 'new' analytical approach [it] will fail miserably to understand" IR (Sterling-Folker, 2005: 33). Figure 2 idealtypically depicts these different views on what global governance can offer IR.

So far the reader might think that global governance remains diffuse, slippery and ambiguous because different meanings exist and the relationship between the subfield of IR and the "new contender" has never been defined. To be more precise, though, it is not so much the fact that different meanings exist or different conceptualizations carry different disciplinary implications, which create and maintain the current state of confusion. Rather, the confusion is a consequence of imprecise and incautious references to an ambiguous concept that, as it stands, does not carry a single meaning. Put differently, it is not the fact that different meanings exist but their non-reflective condensation which leaves us confused. At the same time, however, global governance and its semantic condensation fulfills important rhetorical and disciplinary functions such as connecting ideas and different meanings between and beyond IR (Kaufer and Carley, 1993: 223-224). Thus, although we lack a clear answer to what global governance is, it nevertheless exercises a certain attractiveness in our everyday engagements with world politics and proves to be useful in its own way. Featuring a high degree of "situational conductivity", one can argue that it is the very ambiguity of global governance as a "condensation symbol" to

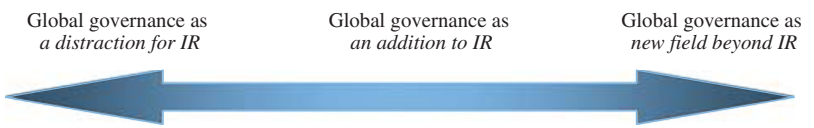

Figure 2 | Ideal Type Assessments on the Relationship between IR and Global Governance.

which we can ascribe all our hopes and visions which makes it so attractive in the first place. Put differently, its open and floating nature invites engagement and dialogue, constitutes identity, allows to account for ongoing change, and makes it overall a relevant narrative to reconcile with.

On the basis of this more optimistic reading of the current state of global governance scholarship while sharing the frustration about the confusion surrounding it, attempts to reduce the concept to a particular meaning do not appear to be the most preferable strategy of sharpening its analytical value. For the most part, those involved in global governance during "the early years" intended to develop new research agendas beyond the formalistic focus on states and intergovernmental organizations. Not being interested or not being able to develop a comprehensive theoretical framework, which integrated different agendas, however, scholars advanced the concept on different levels and with different interests in mind. In an attempt to organize existing understandings without reducing them to a single definition, the following subsections explore and relate different meanings ascribed to global governance. It is argued that different understandings reflect ideal types in a matrix constituted by varying degrees of normative and/or analytical commitment as well as differing assessments on the relationship between IR and global governance based on one's view of the discipline as such. Put differently, all contributions to and applications of global governance in one way or another, explicitly or implicitly, position themselves along these lines (Dingwerth and Pattberg, 2006; Hofferberth, 2015). While such positioning has immediate consequences for one's research and findings in and of global governance, in the absence of definitive arguments for one or the other, none of the understandings can claim superiority as the concept is constituted by different commitments (Jackson, 2015: 946). ${ }^{5}$

Global Governance between policy notion, analytical tool, and empirical condition. The idea of global governance, as will be shown in detail below, "was born from a marriage between academic theory and practical policy" (Weiss and Wilkinson, 2014a: 208). More importantly, both frustration and disappointmentWeiss (2000: 796) speaks of "disgruntlement" and "dissatisfaction"-as well as optimism and high hopes for change were its midwives (Rosenau, 1992). In intellectual terms, conventional ways of studying global issues were challenged while, in political terms, traditional measures to solve them were deemed as failing. Consequentially, global governance was introduced as a perspective for studying as well as for making world politics. Recognizing a scholarly obligation to not only "enhance understanding of the world" but also to "identify levers than when manipulated can facilitate progress towards more humane and normatively desirable ends" (Lake, 2011: 465), global governance, at least in some readings, became problem-driven instead of theory-based research. To improve world politics and provide "good governance" or at least a better provision of public goods in light of transboundary challenges and global injustices, the explicit embrace of normativity to many appeared not only necessary but also was considered as the strongest asset of global governance (Weiss, 2013: 8-13).

As such, we can perceive different understandings in use today as a function of how much global governance one empirically sees 
in current world politics combined with the normative notion of how much one wants (Hofferberth, 2015: 608-614). Obviously, these different understandings relate to each other. In fact, they mutually reinforce each other as shifting policy views shape research agendas and vice versa. Assuming the failure of states and international organizations as ordering principles, academics as well as policymakers in the early $1990 \mathrm{~s}$ turned towards other actors (Sinclair, 2012: 15-17). Declaiming a "new world" and assessing that there was "no alternative to working together and using collective power" to govern this world (Commission on Global Governance, 1995: 2), global governance as a policy notion emphasized the importance of individuals and considered non-state actors such as NGOs, civil society movements, and multinational enterprises as responsible and legitimate players in world politics, which was soon to be echoed in empirical research on these actors. ${ }^{6}$ In particular focusing on NGOs and civil society, scholars stated their potential to change world politics for the better since they could offer "what the world needs now" (Florini and Simmons, 2000). Framed within the optimism of social constructivism and its resurrection of international norms, civil society became the ideal norm entrepreneur to construct a global culture and promote change on the global level (Finnemore and Sikkink, 1998; Boli and Thomas, 1999; Risse et al., 1999).

Underlying such work was the basic yet far-reaching assumption that including more actors and in particular more non-state actors would constitute a global public domain that provided better governance (Ruggie, 2004). In rhetorical figures, authors argumentatively referred to globalization-a highly ambivalent and diffuse notion itself (Scholte, 2005) and were quick to state the limitations states faced in an increasingly globalized world in which borders assumingly lost their meaning. ${ }^{7}$ Portrayed as being no longer able to provide security and welfare for its citizens, states had to accept the functional necessity to include non-state actors and take advantage of their resources, both material and ideational. More a normative than an empirical argument, global problems were perceived as tractable and manageable issues while their solutions were discussed in technical rather than political terms. ${ }^{8}$ Global governance in this context "led scholars to posit the possibility of alternative governance forms that can produce both effective and legitimate outcomes, a sterling instance in which theoretical and empirical analysis is married to practical politics" (Barnett and Sikkink, 2008: 79). In a nutshell, given the immense resources non-state actors commanded, it was argued that their integration into governance structures based on deliberation and cooperation between different stakeholders could provide more effective and more legitimate governance beyond the nation-state (Börzel and Risse, 2010: 126-128)

While losing some of its argumentative momentum through the publications of critical work on the role of NGOs (Sell and Prakash, 2004; Sending and Neuman, 2006) and in particular on business (Brühl, 2007; Fuchs and Lederer, 2007), we still find in many global governance contributions a foundational believe in the value of deliberation and cooperation between different actors providing different resources for governance. Offering comprehensive research designs to determine the legitimacy and efficiency of governance initiatives, the basic assumptions that world politics is no longer the sole domain of nation states, that other "global governors" have entered the arena, and that these actors, if carefully integrated, exercise authority in legitimate ways, are rarely challenged (Avant et al., 2010). As such, while only few contributions explicitly think of and advance global governance as a policy notion, functionalist beliefs and affirmative assumptions continue to radiate into and influence the discourse on global governance, which continues to represent "a yearning of some sort" (Sinclair, 2012: 1). ${ }^{9}$
Contrary to this affirmative approach, we find a sceptical body of literature that also understands global governance as a policy notion but is motivated by worries about and resistance against its current manifestations. Whether global governance is disapprovingly discussed as "liberal hegemony" (Friedrichs, 2009) or completely rejected from a Marxist or Historical Materialist perspective (Murphy, 1994; Cox, 1997; Overbeek, 2005), critical voices remind us to discuss not only how much global governance but rather what kind of global governance we want. In such contributions we find critical assessments and normative rejections of the increased integration of non-state actors in world politics. Actors such as multinational enterprises and private military companies contributing to international security (Leander, 2005) or aid agencies motivated by neo-liberal agendas (Duffield, 2012) in this perspective do not offer solutions but are part of the problem. While reaching opposite conclusions as to what needs to be done to improve global governance, what these contributions share with the broader, more optimistic and affirmative mainstream version of global governance is that they too understand it as a policy notion and that the point of studying global governance "is not just to explain the world but to change it" (Cox, 2008).

Given IR's reluctance to embrace normativity and its longlasting fear to "glide into policy science" (Hoffman, 1977: 59), explicit value judgments within global governance, be it in favour of or in opposition to the current order, made mainstream scholars feel uncomfortable about it. Hence, there have always been attempts to sharpen the analytical value of global governance by separating analysis from assessment. In an effort to reduce its normative commitments, authors stressed the heuristic and theoretical value of global governance as an analytical precept, which soon became "a vantage point designed to foster a regard for the immense complexity and diversity of global life" (Hewson and Sinclair, 1999: 7). Just as other IR theories, global governance began to advance ontological claims about world politics. These included the polyarchy of governance, the complexity of global issues and a diverse set of actors involved in these issues. While representing "ontological wagers" in the first place, these assumptions eventually became "empirical facts". These are now advanced to justify a perspective that allows to study how different actors contribute to the solution of complex problems on different levels of governance. As such, the confusion surrounding global governance originates in the conflation of empirical description and theoretical explanation, which leaves the concept in a tautological circle of interference as "we see empirically what we assume theoretically" and vice versa (Hofferberth, 2015: 610). Instead of a full-fledged research tradition, we find global governance to be stuck in a "theoretical interregnum" (Pegram and Acuto, 2015) and representing, at best, a "theory [still] in the making" (Dingwerth and Pattberg, 2006: 189). ${ }^{10}$

These conceptual challenges that exist for and within any theoretical approach aside, global governance as a heuristic device still serves as an important lens to capture dynamics of world politics that would otherwise remain unseen. It provides the analytical means necessary to take relevant actors and important processes beyond state interaction and the exercise of formal-legal authority into consideration. In other words, despite shortcomings and the conceptual confusion following from them, global governance can be advanced as an analytical perspective and provides new insights which makes it "too important to just let go" (Dingwerth and Pattberg, 2006: 198). Other than conventional IR theorizing, global governance goes beyond a state-centric conceptualization of world politics as IR and offers a broader approach to include different actors, different issues and different modes of exercising political authority (Lake, 2010: 594-596). More importantly and unfortunately adding to the confusion we are facing today, global governance, from its very beginning, intended to describe, understand, and explain process, change and 
transformation on the global scale. Hence, as an analytical tool, it had to be thought of and designed as inherently dynamic and conceptually flexible (Weiss, 2000: 808). Given its fluid nature, it comes as no surprise that different authors using global governance as a heuristic device conclude on different degrees of diffusion and dilution of state power and its respective dispersion among a broader range of new actors (Jentleson, 2012: 134-136).

Ultimately though, as global governance became both the question and the answer to "what makes the world hang together" (Ruggie, 1998), for many it never fully realized its value as an analytical tool precisely because it failed to develop a theory of global order and transformation. While " $\mathrm{t}]$ he strand of thinking about world politics as global governance that comes closest to a theory is essentially linked to the work of Rosenau" (Dingwerth and Pattberg, 2006: 189), most agree with Smouts (1998: 81) who argues that global governance remains for the most part a descriptive account which in the end "betokens no major epistemological breakthrough". Consequentially, moving to the bottom right corner of our ideal-type triangle, we find the majority of contributions understanding and framing global governance as an empirical condition. Presented as a fact and undeniable consequence of world politics in a globalized world in the absence of a world government, global governance is often advanced to describe rather than explain "whatever international order, stability, and predictability exists despite the lack of a central authority" (Weiss, 2013: 1). Put differently, said order is captured in descriptive rather than explanatory terms as global governance lacks systematically derived arguments on why change occurs or why a particular new global order emerged, at least in the sense other IR theories provide (however limited) foundational assumptions about the behaviour of actors and systemic dynamics derived there from. This remains a task not completed yet within global governance thinking as Weiss and Wilkinson (2014a: 211) put it:

We should not only describe who the actors are and how they connect to one another, but also how a particular outcome has resulted and why and on what grounds authority is effectively or poorly exercised. ${ }^{11}$

As an empirical condition of current world politics, global governance and the exercise of authority within is oftentimes presented in somewhat static ways. Because of the absence of theoretical commitments, complexity as the main feature of our modern world is observed and stated rather than "disaggregate[d] by issue and by context" to then be explained (Weiss and Wilkinson, 2014a: 211). We also lack theoretical categories to extent the concept of global governance to study past manifestations of order and compare them in a systematic way (Murphy, 2014). Other than reference to a contemporary diversity of actors and the complex nature of current problems, we find a certain disregard for agency in global governance as we became more interested in its present structure rather than theorizations of how actors become involved and how their relationships and dynamic interaction matter (Avant et al., 2010; Finnemore, 2014). In simple terms, in our structural understanding, global governance is instead of being made. Bringing the different understandings together now that they have been elaborated, global governance became the response to as well as the consequence of living in a globalized world (Held and McGrew, 2002). Whether we assess global governance as "more orderly and reliable responses to social and political issues that go beyond capacities of states" (Gordenker and Weiss, 1996: 17) or a condition that remains best described as a "piecemeal [and] haphazard formation of global regulation" (Murphy, 2000: 803), as well as how we advance and apply the concept in our own research, can be thought of as a function of how much global governance one sees in current world politics combined with the notion of how much of it one wants.

Distraction, addition or saviour-the relationship between IR and global governance. Each of the understandings outlined above emerged in and added to disciplinary debates occurring within the rather fluid Political Science subfield of IR (Jackson, 2015: 942-945). If we agree that the subfield is mainly concerned with (and to some extent defined by) the exercise of political authority on a global scale and, at least in its traditional framing, understood this to be the exclusive domain of states as suggested by its given name, we can consider global governance, independent of its precise meaning, as a critique of IR and driven by the notion to change and expand the field. Put differently, how one understands and advances global governance is, in addition to what has been discussed above, also a function of how intellectually disappointed one is with IR and whether one wants to remain within it or go beyond (Hofferberth, 2015: 611-614). Those who consider the subfield to be alive and well see global governance as a distraction focused on "imagined dragons and genuine fire-breathers" (Sterling-Folker, 2005: 26). More moderate accounts emphasize the relevance of established approaches to account for the dispersion of authority between diverse actors yet at the same time recognize potential in new additions (Karns and Mingst, 2010: 35-62). Finally, assuming collective disciplinary failure, Weiss and Wilkinson (2014b) among others see in global governance the potential to fundamentally reinvent the discipline.

Global governance is thought of as a distraction because the inclusion of non-state actors and new forms of political authority in the end is still outdone by the undeniable fact of international anarchy and competition among states (Waltz, 1999; Gilpin, 2002). In simple terms, since global governance does not represent a world state, it has not changed the nature of IR. Assuming that the underlying dynamics of power politics have not changed, the ability to govern based on political authority for the most part remains centralized within the state while interdependence remains limited (Krasner, 1993). International organizations as well as non-state actors, ultimately, present false promises and unrealistic hopes for international cooperation (Mearsheimer, 1994). Given that IR has always dealt with issues of governance, global governance sceptics argue that one should not overstate the novelty of current developments as change remains much more limited than claimed in approaches, which tend to confuse theoretical assumptions with empirical facts. Instead of emphasizing change, global governance needs to overcome its disregard for power and realize that states are still the main actor in IR (Sterling-Folker, 2005: 33). ${ }^{12}$

More moderate accounts would argue that there are certain changes in the way governance and public goods are provided on the global scale that cannot be denied. Since these changes demand from us to reconsider our mode of thinking, they imply certain consequences for the discipline. Among these changes, IR needs to include and discuss a new diversity of actors involved in world politics as well as consider new topics such as human rights in general (Pegram, 2015) or migration in particular (Geiger and Pécoud, 2014). However, agreeing with the sceptics, these changes and additions can best be accommodated within IR, if only its core concepts like power (Barnett and Duvall, 2005) and authority (Lake, 2010) are broadened and sharpened. In this perspective, global governance becomes somewhat hybrid as it connects to established paradigms and research traditions while providing foundation and intellectual rational for creating a new one (Hoffmann and Ba, 2005b: 257-258). While there is no need to reinvent the wheel to account for global governance, established paradigms and perspectives have to be modified and 
expanded. As an addition to IR, global governance "would have to consider both centralized and decentralized forms of governance". If it does, it provides a "worthy alternative to anarchy because of its ability to interrogate enduring, heretofore neglected, and emerging issues in the theory and practice of international relations" (Barnett and Sikkink, 2008: 78). What remains to be assessed is how exactly "traditional IR theory has responded to the 'new' dynamics of global governance as well as how the phenomenon of global governance has inspired theoretical innovations in IR theory" (Hoffmann and Ba, 2005a: 2). ${ }^{13}$

Finally, reflecting a position that is most dissatisfied with IR, we find authors who argue that the full potential of global governance can only be realized once it leaves behind the limitations and restrictions of a discipline focused at its core on state interaction which holds on to the ideal of empirical rather than normative research. Both have turned IR into an obsolete discipline as scholars engage in academic exercises unrelated to real-world challenges. Thus, as advanced in more recent "mission statements", global governance appears to be more than just studying non-state actors and their governance contributions within the established field of IR (Barnett and Sikkink, 2008; Weiss and Wilkinson, $2014 \mathrm{~b}$ ). Instead of artificially keeping this field alive, the argument goes, global governance allows one to go beyond limited terminologies and theories to transform IR in both intellectual and institutional terms. The introduction of Global Governance in 1995, a "quarterly sought to return to the global problem-solving origins of the leading journal in the field, which seemed to have lost its way" (Weiss and Wilkinson, 2014a: 208), marked an early step in this transformation, which continues today as we see explicitly dedicated centres, workshops, and conferences on global governance proliferate and specialized degree programs institutionalized (Hoffmann and Ba, 2005a: 5). ${ }^{14}$

Obviously, depending on personal assessments of IR and its intellectual capacity, these fragmenting developments present either great potential or great danger. Obviously, advocates of separating global governance from IR argue that the empirical transition from IR to global governance has to be echoed by a transition of its intellectual structures as well. More specifically, they advance two related arguments. First, assuming widespread change in world politics and global governance gaps, the reluctance of IR to embrace normativity needs to be overcome (Weiss, 2000). In this sense, global governance features the potential to radically "improve our discussions by being more explicit about our processes of ethical reasoning and by relating our research findings more explicitly to their normative implications" (Barnett and Sikkink, 2008: 77). Second, advocates for disciplinary reinvention emphasize the potential of interdisciplinary connections. Global governance in this perspective should not only include Political Science theories of governance. Instead, the newly created field could establish closer ties to history by discussing different epochs of global governance (Murphy, 2014), connect to technology sciences to account for complexity of large systems (Mayer and Acuto, 2015), or, more broadly, develop "a sociology of global life" focused on "daily life in thoroughly altered circumstances" (Hewson and Sinclair, 1999: 6-7). All of these are obviously developments to which IR needs to respond intellectually and institutionally.

\section{Global governance and its two overlapping contexts of emergence}

Not arguing in favour of any particular understanding of the above, the remaining section discusses the origins of the different meanings to advance the discussion in and of global governance, reveal disciplinary practices and biases in current debates, and shed some light on how we can arrange ourselves with the confusion surrounding global governance. Unlike globalization
(James and Steger, 2015), global governance is a notion seldom used in public discourse. As a technical term, it is almost exclusively reserved to two overlapping communities of practice: The practitioner's discourse on the one hand and its academic reflection on the other hand (Weiss and Wilkinson, 2014a: 208). However, between these two, there are no clear borders-at least in ideational terms-and meaning easily permeates between them. More importantly, both communities are influenced by real world as well as intellectual developments. Individually and taken together, they consist of "people who share a concern, set of problems, or a passion about a topic and who deepen their knowledge and expertise in this area by interacting on an ongoing basis" (Wenger et al., 2002: 4). Put differently, the fact that some are driven by practical concerns whereas others are approaching global governance from within academia does not prevent them from being influenced by the same real-world and intellectual contexts and dynamics. While influencing each other, the following two subsections discuss real-world and disciplinary developments to account for the confusion surrounding global governance today.

The real-world context \& its dynamics. In an immediate sense, the emergence of global governance was influenced and motivated by the end of the Cold War. Living in "a time when hegemons are declining, when boundaries (and the walls that seal them) are disappearing, when squares of the world's cities are crowded with citizens challenging authorities" (Rosenau, 1992: 1), contemporaries, both practitioners and academics alike, felt that they experienced a turning point in history. Reference to this historical event not only became a popular first line for publications in the 1990s. It also became an intellectual point of orientation and bestowed scholars with an identity and new themes to study. Contemporary transformations were thus perceived with enthusiasm as well as with anxiety. In their first editors' note of Global Governance, Coate and Murphy (1995: 1) for example argued that it was a time of "great hope and great hopelessness, a time when ideological fault lines have disappeared, while the global rifts of wealth and power have widened". Hence, while assessments and perceptions of the realworld changes remained ambiguous, everyone agreed their time marked a unique turning point in history as assumed givens in the pattern of global governance changed in a rather dramatic fashion (Hewson and Sinclair, 1999: 3-5). ${ }^{15}$

The end of the Cold War, important as it was for global governance thinking and practice, however reflects only a larger, more foundational development that affected and continues to affect the "deepest sense of human condition" (James and Steger, 2015: 16). Being both an old and a new phenomenon and in its incipient form obviously present before the 1980s, globalization at this time reached a new quality. All spheres of life-culture, communication, and travel, production and markets, money and finance, ecology and health-accelerated to the extent that practitioners and scholars were exposed to global dynamics unlike before (Scholte, 2005: 101-120). Providing a catchword to describe and understand contemporary processes of time and space compression of social relations and the means to make sense of individual experiences, hopes and anxieties of living in a globalized world, globalization became the most fundamental "claim about the nature of 'our time" " and hence determined the way practitioners and academics constructed their worlds (James and Steger, 2015: 16). For the first time in the lifespan of an entire generation, change and transformation rather than stability and continuity had to be explained and politically dealt with. Both practitioners and scholars embraced this opportunity to show how, because of globalization, traditional ways of thinking and making world politics had reached an impasse (Weiss and Wilkinson, 2014a: 208). ${ }^{16}$ 
More specifically, practitioners and academics gave meaning to the notion of globalization by referring to living in a globalized world as living in a world of "increased complexity". Previous ordering principles, such as the state or international organizations, were deemed to have failed as national problems became global problems and politicians and academics alike felt helpless to grasp let alone govern these issues anymore (Sinclair, 2012: 1517). On the basis of this feeling of being overwhelmed, much of what was only perceived and assumed in the first place quickly became an academic and political argument, which then further contributed to the confusion of the time. Put differently, the changing nature of global problems, the new role of non-state actors and the limitations of traditional modes of governance were all rather "felt" than proven. On the basis of these experiences, real or perceived, global governance became the intellectual shortcut and political answer for living in and dealing with a new, more complex world. As will be shown in the next subsection, the perceived novelty and far-reaching changes of contemporary developments and experiences, influenced advocates to focus more on broader themes instead of spelling out details. This can be explained psychologically by living in an exciting time of change, hope, and fear instilled by, and interpreted based on the perception of fundamental and historically unique change. In a nutshell, enthusiasm as well as desperation translated an ambiguous historical context into an ambiguous analytical concept (Hofferberth, 2015: 602).

The disciplinary context and its dynamics. The study of governance and order on a global scale obviously has always played an important role in IR thinking. Hence, in intellectual terms, there is no clear starting point and we can think of global governance as a rather old notion (Hoffmann and Ba, 2005a: 2-3). However, given contemporary experiences of fundamental change and the perception that both states and international organizations were not accommodating these changes adequately, various authors during the early 1990s "bundled" certain elements of studying world order anew and thereby created what later came to be known as global governance. In disciplinary terms, five widely shared assumptions and commitments stood out in particular which, taken together, distinguished this new narrative from traditional approaches: (1) the perception of governance problems to be potentially global in nature and hence the need to find new, potentially global solutions, (2) the analytical need to consider other actors beyond the state providing such solutions, (3) the notion that "order" and governance are not established and provided only through formal-legal authority (4) the assumption that "order" and governance are constantly undergoing change, and (5) the articulation of an explicitly normative interest to direct this change. While each element was not unique to global governance, taken together they constituted a new approach whose origins can be dated back to the early 1990 s and which soon gathered intellectual momentum in and beyond IR (Hewson and Sinclair, 1999: 3-5).

Introduced into a discipline suffering from and struggling with its self-made straightjackets of state-centrism, paradigm wars and rationalism, this new approach, despite its vagueness and the multiple meanings it carried, quickly gained space and established a new narrative to be reckoned with. Broadly speaking, global governance substantially connected to the study of intergovernmental organizations, international law, and transnational actors (Sinclair, 2012: 13-24). To provide a comprehensive account, global governance also had to connect to and position itself vis-àvis other theories and approaches entertained in the early 1990s as well as intellectual trends influencing the discipline at that time. Considering the disciplinary context of IR in the 1990s, three developments during the emergence of global governance stood out in particular: (1) the continuous decline and ultimate annexation of the English School, regime theory and the study of transnational actors by global governance (2) the non-normative commitment in mainstream IR towards rigorous analytical theorizing and (3) the emergence of (social) constructivism in response to this and the opening of the discipline to alternative knowledge claims.

The "annexation" of the English School, regime theory, and the study of transnational actors. For the intellectual history of global governance, the English School, regime theory and the study of transnational actors stand out in particular as each served as an intellectual predecessor, which had to be reconciled with. Sharing a deep research interest in the role of social institutions and actors beyond the nation-state, the different approaches collectively carried the notion of broadening the study of IR by introducing compelling alternatives to state-centric approaches focused on power politics. Given this overlap, different authors were simultaneously involved in all three discourses and each of them represented intellectual as well as personal reference objects for the new contender in the intellectual landscape of IR. At the same time, global governance scholarship, through the politics of disciplinary definition making and boundary charting, differentiated itself from previous approaches, created its own intellectual momentum, and thereby established its hegemonic status. ${ }^{17}$ It was able to do so because in the 1990s, each approach was, intellectually speaking, in decline and received less attention in the discipline. This allowed global governance to draw from them while establishing its own intellectual narrative. The English School in particular, having "laid the foundations of a very broad ranging research agenda" whose "parameters, however, have been no more than hinted at" (Little, 2000: 414) proved to be an important intellectual stimulus for thinkers such as Rosenau and others. However, the fact that mainstream IR was no longer interested in the English School plus the perception of living in a historically new situation allowed global governance to "intellectually annex" the English School through a side note reference:

$[\mathrm{M}]$ ost prior attempts to delineate global order [referring, among others, to Bull's Anarchical Society] have not been propelled by a world undergoing change in the fundamental arrangements through which the course of events unfolds. Our advantage is the perplexity induced by recent developments, an awe that enables us to pose questions that might not otherwise get asked and to identify alternative lines of development that might otherwise not get explored. (Rosenau, 1992: 2)

Despite the "striking parallels between the governance paradigm and the idea of international society which came to dominate international-relations thinking in Britain after 1945" (Dunne, 2005: 72), there are few other references to the English School in early global governance thinking. The same can be concluded for regime theory despite its "significant impact on scholarly thinking in the 1980s" in general and its focus on governance in particular (Hewson and Sinclair, 1999: 11). By arguing that governance was "the more encompassing concept" whereas regime theory remained limited to specific issue areas (Rosenau, 1992: 8), we yet again find limited connections and conjunctions. Apparently, to establish its uniqueness and relevance, global governance emphasized its novelty more than its intellectual connections to existing ones (Lake, 2011: 467-469). Instead of reference and exchange, which could have clarified the specific analytical contributions global governance had to offer, we see only loose references and intellectual distinction, leaving the 
concept to be associated with different meanings as presented above. In what one has to describe as an elegant strategic move, though, global governance drew from and at the same time superseded both research traditions as they were struggling to maintain relevance in the IR discourse and ultimately annexed and monopolized their topics and themes. ${ }^{18}$

As to the study of transnational actors, the annexation played out even easier since this field of study was never established as a research tradition and for the longest time remained "relegated to the sidelines of theorizing on either side of the Atlantic" (Risse, 2002: 257). While being discussed in IR as early as the late 1960s and culminated into the seminal collection of essays on transnational actors first published as an International Organization special issue in 1971 and then later as an edited volume (Keohane and Nye, 1973), the notion to challenge IR's state centrism by systematically considering non-state actors never translated into a clear research programme. Nevertheless, global governance benefitted from these debates and the intellectual space created thereby as arguments made earlier became the "signature move" of global governance. Again, global governance connected to yet at the same time reframed the study of transnational actors. For those who already studied transnational actors, global governance offered a new perspective to relate to and to re-state the relevance of their studies. For those who argued against their consideration, global governance appeared to be a much larger contender than previous approaches as the renewed interest in transnational actors immediately connected to real-world developments and thereby made a stronger case than ever before (Avant et al., 2010).

Overall, while entertaining intellectual proximity and thematic resemblance with different traditions, early proponents of global governance appeared to be reluctant to fully embrace any of them but rather distinguished their new approach. Whereas there was enough overlap to connect to previous debates, global governance at the same time appeared to be different enough to justify a new approach. It can thus be argued that much of the attractiveness that made global governance climb from the "ranks of the unknown to one of the central orienting themes in the practice and study of international affairs" (Barnett and Duvall, 2005: 1) originated in finding the sweet spot between drawing on, yet at the same time differentiating itself from, other approaches. It is also safe to assume that this rhetorical strategy of simultaneously connecting to and distinguishing from other approaches further contributed to the confusion that haunts global governance today as it remained "open and diffuse, if not a little noncommittal" since these characteristics were perceived as "attractive qualities in an era of ambiguity, uncertainty, and flux" (Latham, 1999: 24).

The non-normativity of mainstream $I R$ and the emergence of (social) constructivism. With the second great debate-if it ever occurred at all-ending in favour of the behaviouralists (Waever, 1997) and with positivism becoming the dominant philosophy of science in IR (Jackson, 2011: 32-40), analytical theorizing and the rejection of normative commitments to policy goals became the intellectual ideals of IR during the 1980s and 1990s. ${ }^{19}$ Just as its flagship publication International Organizations, the discipline as a whole at this time "increasingly drew back from matters of international policy and instead became a vehicle for the development of rigorous academic theorizing" (Sinclair, 2012: 16). Formal methods and the notion "to count what we could to make sense of the world" (Weiss and Wilkinson, 2014b: 22) became integral to the study of world politics. Such a heavy reliance on a particular philosophy of science, however, opened a window of opportunity, both for global governance and (social) constructivism. While mainstream IR had become very sceptical of any sort of value commitment, global governance proponents and constructivists were not shy to discuss the possibility of a "better world". In particular, global governance succeeded in turning its normative commitments into one of its defining characteristics and assets. Important questions such as "what forms of organization and governance should prevail, how scarce resources should be allocated, and what kind if policy ought to be put in place" were raised, discussed and answered exclusively within global governance (Weiss and Wilkinson, 2014b: 22).

Such normative commitments were integrated into the broader critique on mainstream IR, its philosophy of science, and its methods. Considering global governance in this context as something more than a set of ontological claims, we find clear overlaps and yet again a curious lack of explicit references between constructivism and global governance. In his opening chapter, Rosenau (1992: 18-19) argued that "the essential dynamics of any global order are, in effect, both independent and dependent variables in the endless processes whereby the patterns that constitute the order are maintained" and hence pleaded to "eschew [...] the scientific procedure of designating independent and dependent variables, replacing it with a method of sensitivity to the interactive complexity of global order". In other words, both constructivism and global governance wanted to avoid the pitfalls of structural determinism and reductionism and rejected simple causality in favour of accounting for more complex interrelations. Whereas this translated into the mutual co-constitution of agency and structure for constructivism (Wendt, 1999), the underlying mantra for global governance became complex polyarchy instead of formal hierarchy (Barnett and Sikkink, 2008: 70-73).

Overall, in its methodological, ontological, and epistemological claims, constructivism and global governance advanced rather similar ideas. However, whereas constructivists advanced their arguments from a more theoretically inspired perspective and explicitly included methodological and epistemological implications, global governance was more concerned with real-world changes and their substantial implications for world order. Liberating itself from potentially sterile and intellectually debilitating debates on methodology and epistemology, global governance scholarship became for the most part empirically driven. Hailed by those involved for its openness to incorporate different methods and epistemologies, global governance at the same time, because of its non-commitment, remained at odds with the theoretical landscape of IR as it did not connect to and position itself on all layers necessary for establishing itself as a paradigm (Hoffmann, 2005). ${ }^{20}$ In this context, despite limited reference and exchange between constructivism and global governance, their parallel emergence created intellectual space and opened up the discipline towards new knowledge claims and themes, which both took advantage of albeit in different ways. More specifically, one can argue that there was an implicit division of labour between these two approaches: Constructivism saved global governance from fighting methodological and epistemological battles and allowed the new contender to focus on substantial issues of world order and change instead. Overall, however, together with the explicit wish to combine analytical and normative commitments, its undecided and non-committed status in the landscape of IR theory further contributes to and explains the confusion surrounding global governance today (Hofferberth, 2015: 603-604).

\section{Conclusion}

The intention of this article was twofold. First, by systematizing and structuring different uses of global governance in IR, current discussion within the subfield was meant to be structured while "disciplinary outsiders" were invited to better understand and ultimately contribute to this discussion themselves. As was 
shown, the scope and purpose, as well as the main research interests of global governance scholarship, are as diverse as the subject under consideration and shifted over time, leaving the uninitiated as well as those involved in the field in a state of confusion about its precise nature and conceptual status. Second, the article attempted to advance the discussion by offering explanations for the confusion plaguing the discussion today. In this context, the interpretation on the evolution of global governance scholarship is provided in retrospect and does not capture or reflect the experiences, motivations and intentions, of those involved. Rather, it discussed the discourse as it collectively presents itself today and engaged with both the consequences and the sources of the confusion expressed within. Despite this state of confusion, the article did not offer yet another definition of global governance. Moreover, it did not assess or rank the different understandings of global governance detailed above. This reason for this is simple and should be clear by now: any attempt to reduce global governance to a singular understanding remains arbitrary and hence constitutes a problematic disciplinary since disciplining intervention. Consequentially, we should rephrase Finkelstein's notorious question and discuss what is meant by global governance in a particular context, relax our desire for definiteness, and overall advance the concept more cautiously to preserve its attractiveness and inherent plurality, which it offers as a condensation symbol to improve dialogue between proponents and opponents of the concept, in and beyond IR (Dingwerth and Pattberg, 2006: 198-200).

It was argued that perceiving global governance as a condensation symbol provides the foundation to accept confusion as a fundamental state of mind while still ensuring application and progress. Plurality of meaning in this context can even be considered as an asset rather than failure if everyone involved accept the responsibility "to be more explicit about their individual usages of the term if the current debate is to become more analytically fruitful" (Dingwerth and Pattberg, 2006: 198). Obviously, any contribution including this one unintentionally and by selection bias drives certain stakes and cornerstones into the discourse. However, assuming that the discourse of global governance is alive and kicking, structuring proposals such as this one remain by definition preliminary. However, they remind us that certain power relations are at play in any attempt of defining global governance once and for all in its "true meaning" (Kaufer and Carley, 1993). Revealing these definitions and other problematic practices ironically adapted from IR while breaking away from it, appears to be the most productive approach if one wants to pursue the notion of establishing global governance as a new field beyond IR or, more modestly, establish global governance as a conceptual alternative in IR. Either way, being reflective on the subfield as it is practiced today and becoming aware of the peculiar intellectual career of global governance can only help in this context to advance the concept more cautiously (Lake, 2011; Jackson and Nexon, 2013).

Do such concerns justify the navel gazing this contributions immersed itself in while important and pressing issues remain abundantly present in the global context? I would argue it does, simply because of the higher stakes implicated by the ongoing attractiveness of global governance. The lack of clarity and caution in the last years did not slow down the momentum of global governance and it appears unlikely that this will happen any time soon despite the confusion everyone laments over (Barnett and Sikkink, 2008; Weiss and Wilkinson, 2014b). Thus, while the diversity of understandings and research interests might indeed be healthy for global governance scholarship, we have reached a point were further imprecision or arbitrary interventions of disciplining are consequential. In addition, just as with the notion of globalization, tracking empirical processes of global governance without understanding its conceptual emergence and current uses remains limited since precisely this reminds us that there are other ways of studying the phenomena (James and Steger, 2015: 15). Global governance's peculiar reluctance to consider periods and epochs before the real-world and disciplinary contexts in which it was named (Murphy, 2014) as well as the lack of theorizing agency and interaction (Finnemore, 2014) comes to mind as pressing intellectual issues. Accepting the inherent confusion of global governance appears to be the most promising way to pursue such issues as well as others as the future of IR as an intellectual enterprise, thanks to global governance, is now more open than ever.

\section{Notes}

1 The title is a reference to a Bad Religion song in which the challenges of maintaining one's sanity in today's world are described. It continues with the following line that summarizes how both proponents and opponents of global governance sometimes feel about it: "It doesn't really matter what I'm figuring out, I'm guaranteed to wind up in a state of doubt".

2 Lake (2011: 468) rightfully makes the argument that generic references such as "Waltz 1979", "Keohane 1984" or "Wendt, 1999" are also of limited value when making detailed arguments about world politics. However, those traditional research traditions at least share a figurehead to which one can refer to and whose meanings and understandings of world politics one can engage with. While many contributed to the debate, no single author represents global governance as much as the referred authors reflect "their" research traditions.

3 Weiss (2000) for example refers to "conceptual and actual challenges" for and within global governance to state that the latter are to be prioritized.

4 Just as with International Relations, the use of capital letters could already help clarify whether we talk about the real-world object of study (that is, global governance) or the collective academic enterprise on it (that is Global Governance). However, not even such a simple practice has been collectively established until today.

5 As with any structuration, the proposal at hand obviously is based on a subjective account and reading of the discourse. Representing a constructivist treatise of global governance and its emergence itself, the article identifies and reproduces cornerstones that to some extent might seem to contradict the inherent plurality that is argued for in this article. While ultimately not able to solve this tension, it is acknowledged and accepted because of the added value that springs from structuring current understandings of global governance. Embracing plurality on this meta-level as well, other proposals and accounts of the concept will hopefully highlight aspects missed here.

6 A more recent example of how specific policies influence research in the study of global governance can be found in the emerging field of inter-organizational relations. Focused on the dynamics between organizations with global and regional mandates, this field mainly studies the European Union and its engagement with(in) other organizations in empirical terms simply because here we find the most advanced policies on the subject (Koops, 2012).

7 Weiss and Wilkinson (2014a: 208) for example connect global governance to "that other meta-phenomenon of the last two decades [known as] globalization" and advance it to explain fundamental change to which global governance had to respond.

8 This distinction might need further clarification and a hypothetical example based on a public-private partnership to provide water for a community can help. A "technical discussion" in this context focuses on how to organize stakeholder dialogue whereas a "political debate" raises the question whom to include as stakeholders in the first place.

9 As (Rosenau (1992: 10) put it, there is always "concern around the desirability of the emergent global arrangements vis-à-vis those they are replacing”. He went on to argue that while "there is a huge difference between empirically tracing the underlying arrangements and analyzing their potential consequences on the one hand and judging the pros and cons of the arrangements on the other", the line dividing these two "can be obscure and variable" (Rosenau, 1992: 10). Hence, even if we find strong preference to keep the analytical and the normative use of global governance separated, the ideal types suggested in Fig. 1 in reality overlap and cannot be thought of as opposites as, even within a single contribution, different understandings may be advanced.

10 Obviously, global governance is not alone in dealing with the challenges that stem from the mutually co-constitutive relation between one's theoretical assumptions and one's empirical observations. As Lake (2011: 470) argues, all theories are caught up in their own observations, which remain subjective to said theory. Shapiro $(2004: 19,28)$ is even more explicit as he calls observations exclusively based on one theory "tendentious characterizations of the phenomena under study" advanced to "vindicating some pet approach".

11 Note the curious absence of an explicit notion to explain particular outcomes in this reference. Explanations of governance, some would argue, are not different from the 
idea describing why authority is exercised and yet Weiss and Wilkinson avoid calling for explanations.

12 Even advocates such as Weiss and Wilkinson (2014a: 211) agree that "giving greater thought to the way that power is exercised" remains an essential task for current global governance thinking.

13 Connecting to the different understandings discussed above, framing global governance as an addition to the field basically strips off its normative commitment and "mainstreams" the concept in the sense that it becomes an empirical condition that needs to be accounted for by and within the different existing theoretical paradigms.

14 The current thematic and theoretical fragmentation of IR commented on by many (Lake, 2011; Jackson and Nexon, 2013) is intensified by the emergence of new and specialized degree programs. Among those, we see programs explicitly carrying global governance in their titles. Consider for example the MSC in Global Governance and Diplomacy at the University of Oxford, the MA in Global Governance at the Florida International University and the Balsillie School of International Affairs as well as many graduate certificates in the United States and elsewhere.

15 A telling example of the practitioner's enthusiasm would be the notion of a "New World Order" picked up and reinforced by George H. W. Bush in an address to Congress on the Persian Gulf crisis in 1990. As to academia, Fukuyama's (1992) "End of History" thesis reveals the same excitement and euphoria.

16 Note that the Commission on Global Governance report echoed and reinforced the notion of globalization by referring to a "global neighborhood" (Commission on Global Governance, 1995).

17 I would like to thank the anonymous reviewers for pointing out these disciplinary dynamics.

18 It is fair to say in this context that while the English School enjoyed and continues to enjoy a certain attention in IR (Buzan, 2001), global governance can be considered as a final nail in the coffin of regime theory.

19 From a critical perspective, one can argue that IR's preferred philosophy of science represented a normative choice in and of itself. Hence, it is more correct to speak of self-claimed rather than factual non-normativity (Cox, 2008).

20 This non-positioning most likely prevented global governance from becoming yet another "-ism". Turning this argument around, the comprehensive positioning of (social) constructivism obviously helped to shape the new contender's profile and related it to other IR theories. At the same time, however, social constructivism's particular answers to the regret of many led to a new "middle ground orthodoxy" in IR (Kratochwil, 2000)

\section{References}

Avant D D, Finnemore M and Sell S K (2010) Who governs the globe? In: Avant D D, Finnemore M and Sell S K (eds) Who Governs the Globe? Cambridge University Press: Cambridge, UK, pp 1-31.

Ba A D and Hoffmann M J (2005) Contending Perspectives on Global Governance. Coherence, Contestation and World Order. Routledge: New York.

Barnett M and Duvall R (2005) Power in global governance In: Barnett M and Duvall R (eds) Power in Global Governance. Cambridge University Press: Cambridge, UK, pp 1-32.

Barnett M and Sikkink K (2008) From international relations to global society In: Reus-Smit C and Snidal D (eds) The Oxford Handbook of International Relations. Oxford University Press: Oxford, pp 62-83.

Boli J and Thomas G M (1999) Constructing World Culture. International Nongovernmental Organizations Since 1875. Stanford University Press: Stanford, CA.

Börzel T A and Risse T (2010) Governance without a state: Can it work? Regulation \& Governance; 4 (2): 113-134.

Brühl T (2007) Public-private partnerships: Unlike partners? Assessing new forms of regulation In: Schirm S A (ed) Globalization. State of the Art and Perspectives. Routledge: London, pp 143-161.

Buzan B (2001) The English School. An underexploited resource in IR. Review of International Studies; 27 (3): 471-488.

Coate R A and Murphy C N (1995) Editors' note. Global Governance; 1 (1): 1-2.

Commission on Global Governance. (1995) Our Global Neighbourhood. The Report of the Commission on Global Governance. Oxford University Press: Oxford.

Cox R W (1997) The New Realism: Perspectives on Multilateralism and World Order. Palgrave Macmillan: London.

Cox R W (2008) The point is not just to explain the world but to change it. In: Reus-Smit C and Snidal D (eds) The Oxford Handbook of International Relations. Oxford University Press: Oxford, pp 84-93.

Dingwerth K and Pattberg P (2006) Global governance as a perspective on world politics. Global Governance; 12 (2): 185-203.

Duffield M (2012) Challenging environments: Danger, resilience and the aid industry. Security Dialogue; 43 (5): 475-492.

Dunne T (2005) Global governance. An English School perspective In: Ba A D and Hoffmann M J (eds) Contending Perspectives on Global Governance. Coherence, Contestation and World Order. Routledge: New York, pp 72-87.
Finkelstein L (1995) What is global governance? Global Governance; 1 (3): 367-372.

Finnemore M (2014) Dynamics of global governance: Building on what we know. International Studies Quarterly; 58 (1): 221-224.

Finnemore $M$ and Sikkink $\mathrm{K}$ (1998) International norm dynamics and political change. International Organization; 52 (4): 887-917.

Florini A and Simmons P J (2000) What the world needs now? In: Florini A (ed) The Third Force. The Rise of Transnational Civil Society. Japan Center for International Exchange: Tokyo, Japan, pp 1-15.

Friedrichs J (2009) Global governance as liberal hegemony. In: Whitman J (ed) Palgrave Advances in Global Governance. Palgrave Macmillan: Houndsmills, pp 105-122.

Fuchs D and Lederer M (2007) The power of business. Business and Politics; 9 (3): $1-17$.

Fukuyama F (1992) The End of History and the Last Man. Avon Books: Los Angeles, CA.

Geiger M and Pécoud A (2014) International organisations and the politics of migration. Journal of Ethnic and Migration Studies; 40 (6): 865-887.

Gilpin R (2002) A realist perspective on international governance In: Held D and McGrew A (eds) Governing Globalization. Power, Authority and Global Governance. Polity Press: Cambridge, UK, pp 237-248.

Gordenker L, Weiss T G (1996) Pluralizing global governance: Analytical approaches and dimensions In: Gordenker L (ed) NGOs, the UN, and Global Governance. Lynne Rienner Publishers: Boulder, CO, pp 17-50.

Held D and McGrew A (2002) Governing Globalization. Power, Authority and Global Governance. Polity Press: Cambridge, UK.

Hewson M and Sinclair T J (1999) The emergence of global governance theory In: Hewson M and Sinclair T J (eds) Approaches to Global Governance Theory. State University of New York Press: Albany, NY, pp 3-22.

Hofferberth M (2015) Mapping the meanings of global governance: A conceptual reconstruction of a floating signifier. Millennium: Journal of International Studies; 43 (2): 598-617.

Hoffman S (1977) An American social science: International relations. Daedalus; 106 (3): 41-60.

Hoffmann M J (2005) What's global about global governance? A constructivist account In: Ba A D and Hoffmann M J (eds) Contending Perspectives on Global Governance. Coherence, Contestation and World Order. Routledge: New York, pp $110-128$.

Hoffmann M J and Ba A D (2005a) Introduction. Coherence and contestation In: Ba A D and Hoffmann M J (eds) Contending Perspectives on Global Governance Coherence, Contestation and World Order. Routledge: New York, pp 1-14.

Hoffmann M J and Ba A D (2005b) Contending perspectives on global governance. Dialogue and debate In: Ba A D and Hoffmann M J (eds) Contending Perspectives on Global Governance. Coherence, Contestation and World Order. Routledge: New York, pp 249-267.

Jackson P T (2011) The Conduct of Inquiry in International Relations. Routledge: New York.

Jackson P T (2015) Must international studies be a science? Millennium: Journal of International Studies; 43 (3): 942-965.

Jackson P T and Nexon D H (2013) International theory in a post-paradigmatic Era: From substantive wagers to scientific ontologies. European Journal of International Relations; 19 (3): 543-565.

James P and Steger M B (2015) A genealogy of "globalization": The career of a concept In: Steger M B and James P (eds) Globalization: The Career of a Concept. Routledge: London, pp 1-18.

Jentleson B W (2012) The John Holmes memorial lecture: Global governance in a copernican world. Global Governance; 18 (2): 133-145.

Karns M P and Mingst K A (2010: 2) International Organizations. The Politics and Processes of Global Governance. Lynne Rienner Publishers: London.

Kaufer D S and Carley K M (1993) Condensation symbols: Their variety and rhetorical function in political discourse. Philosophy and Rhetoric; 26 (3): 201-226.

Keohane R O and Nye J S (1973) Transnational Relations and World Politics. Harvard University Press: Cambridge, MA.

Koops J A (2012) Inter-organisational approaches In: Jørgensen K E (ed.) Routledge Handbook on the European Union and International Institutions. Routledge: New York, pp 71-85.

Krasner S D (1993) Economic interdependence and independent statehood In: Jackson R H (ed) States in a Changing World. A Contemporary Analysis. Oxford University Press: Oxford, pp 301-321.

Kratochwil F V (2000) Constructing a new orthodoxy? Wendt's 'social theory of international politics' and the constructivist challenge. Millennium: Journal of International Studies; 29 (1): 73-101.

Lake D A (2010) Rightful rules: Authority, order, and the foundations of global governance. International Studies Quarterly; 54 (3): 587-613.

Lake D A (2011) Why "isms" are Evil: Theory, epistemology, and academic sects as impediments to understanding and progress. International Studies Quarterly; 55 (2): 465-480. 
Latham R (1999) Politics in a floating world. Toward a critique of global governance In: Hewson M and Sinclair T J (eds) Approaches to Global Governance Theory. State University of New York Press: Albany, NY, pp 23-53.

Leander A (2005) The power to construct international security: On the significance of private military companies. Millennium: Journal of International Studies; 33 (3): 803-825.

Little R (2000) The English School's contribution to the study of international relations. European Journal of International Relations; 6 (3): 395-422.

Mayer M and Acuto M (2015) The global governance of large technical systems. Millennium: Journal of International Studies; 43 (2): 660-683.

Mayntz R (2003) New challenges to governance theory In: Bang H (ed) Governance as Social and Political Communication. Manchester University Press: Manchester, UK, pp 27-40.

Mearsheimer J J (1994) The false promise of international institutions. International Security; 19 (3): 5-49.

Murphy C (1994) International Organization and Industrial Change. Polity Press: Cambridge, UK.

Murphy C (2000) Global governance: Poorly done, poorly understood. International Affairs; 76 (4): 789-803.

Murphy C (2014) Global governance over the long haul. International Studies Quarterly; 58 (1): 216-218.

Overbeek H (2005) Global governance, class, hegemony: A historical materialist perspective In: Ba A D and Hoffmann M J (eds) Contending Perspectives on Global Governance. Coherence, Contestation and World Order. Routledge: New York, pp 39-56.

Pegram T (2015) Global human rights governance and orchestration: National human rights institutions as intermediaries. European Journal of International Relations; 21 (3): 595-620.

Pegram T and Acuto M (2015) Introduction: Global governance in the interregnum. Millennium: Journal of International Studies; 43 (2): 584-597.

Risse T (2002) Transnational actors and world politics In: Carlsnaes W, Risse T and Simmons B A (eds) Handbook of International Relations. Sage Publications: London, pp 255-274.

Risse T, Ropp S C and Sikkink K (1999) The Power of Human Rights. International Norms and Domestic Change. Cambridge University Press: Cambridge, UK.

Rosenau J N (1992) Governance, order, and change in world politics In: Rosenau J N and Czempiel E O (eds) Governance without Government. Order and Change in World Politics. Cambridge University Press: New York, pp 1-29.

Rosenau J N and Czempiel E O (1992) Governance without Government. Order and Change in World Politics. Cambridge University Press: New York.

Ruggie J G (1998) What makes the world hang together? Neo-utilitarian and the social constructivist challenge. International Organization; 52 (4): 855-885.

Ruggie J G (2004) Reconstituting the global public domain. Issues, actors, and practices. European Journal of International Relations; 10 (4): 499-531.

Scholte J A (2005:2) Globalization. A Critical Introduction. Palgrave Macmillan: Basingstoke, IL.

Sell S K and Prakash A (2004) Using ideas strategically: The contest between business and NGO networks in intellectual property rights. International Studies Quarterly; 48 (1): 143-175.

Sending O J and Neuman I B (2006) Governance to governmentality: Analyzing NGOs, states, and power. International Studies Quarterly; 50 (3): 651-672.

Shapiro I (2004) Problems, methods, and theories in the study of politics, or: What's wrong with political science and what to do about it In: Shapiro I (ed)
Problems and Methods in the Study of Politics. Cambridge University Press: Cambridge, UK, pp 19-41.

Sinclair T J (2012) Global Governance. Polity Press: Cambridge, UK.

Smouts M C (1998) The proper use of governance in international relations. International Social Science Journal; 50 (1): 81-89.

Sterling-Folker J (2005) Realist global governance: Revisiting cave! hic dragones and beyond In: Ba A D and Hoffmann M J (eds) Contending Perspectives on Global Governance. Coherence, Contestation and World Order. Routledge: New York, pp 17-38.

Torfing J, Peters B G, Pierre J and Sørrensen E (2012) Interactive Governance Advancing the Paradigm. Oxford University Press: Oxford.

Waever O (1997) Figures of international thought: Introducing persons instead of paradigms In: Neumann I B and Waever O (eds) The Future of International Relations. Masters in the Making? Routledge: London, pp 1-37.

Waltz K N (1999) Globalization and governance. PS: Political Science and Politics; 32 (4): 693-700.

Weiss T G (2000) Governance, good governance and global governance: Conceptual and actual challenges. Third World Quarterly; 21 (5): 795-814.

Weiss T G (2013) Global Governance: Why? What? Whither? Polity Press: Cambridge, UK.

Weiss T G and Wilkinson R (2014a) Rethinking global governance? Complexity, authority, power, change. International Studies Quarterly; 58 (1) 207-215.

Weiss T G and Wilkinson R (2014b) Global governance to the rescue: Saving international relations? Global Governance; 20 (1): 19-36.

Wendt A (1999) Social Theory of International Politics. Cambridge University Press: Cambridge, UK.

Wenger E, McDermott R and Snyder W M (2002) Cultivating Communities of Practice. A Guide to Managing Knowledge. Harvard Business School Press: Boston, MA.

\section{Data Availability}

Data sharing not applicable to this article as no datasets were generated or analysed during the current study.

\section{Additional Information}

Competing financial interests: The authors declare no competing financial interests.

Reprints and permission information is available at http://www.palgrave-journals.com/ $\mathrm{pal} /$ authors/rights_and_permissions.html

How to cite this article: Hofferberth M (2016) Confusion is a fundamental State of mind -On the peculiar intellectual Career of global governance in international relations. Palgrave Communications. 2:15044 doi: 10.1057/palcomms.2015.44.

This work is licensed under a Creative Commons Attribution 4.0 International License. The images or other third party material in this article are included in the article's Creative Commons license, unless indicated otherwise in the credit line; if the material is not included under the Creative Commons license, users will need to obtain permission from the license holder to reproduce the material. To view a copy of this license, visit http://creativecommons.org/licenses/by/4.0/ 